\title{
25 Research Soure \\ Spatial Analysis of Skin Cancer: Separating Body Parts Exposed and Not Exposed to the Sun
}

Parinaz Tabari

Shiraz University of Medical Sciences

Alireza Mohammadi ( $\nabla$ a.mohammadi@uma.ac.ir)

University of Mohaghegh Ardabili

Sayyed Mostafa Mostafavi

Mashhad University of Medical Sciences

Mohsen Moghadami

Shiraz University of Medical Sciences

Mitra Amini

Shiraz University of Medical Sciences

Abbas Rezaianzadeh

Shiraz University of Medical Sciences

Behzad Kiani

Mashhad University of Medical Sciences

\section{Research Article}

Keywords: Skin cancer, Spatial analysis, Spatial autocorrelation, Cluster analysis, Geographical information system, Iran, Fars

Posted Date: February 4th, 2021

DOI: https://doi.org/10.21203/rs.3.rs-153215/v1

License: (a) (1) This work is licensed under a Creative Commons Attribution 4.0 International License.

Read Full License 


\section{Abstract}

Introduction: Skin cancer is among the most common cancer categories with an increasing global trend of incidence rate. This study explores the spatial distribution of skin cancer, considering body sites exposed and not exposed to sunshine separately.

Methods: We used 4302 skin cancer cases recorded by Fars Cancer Registry in southwestern Iran for over six years (2011-2017). The variables included in the study were patients' residence address, gender, age, report date, and final topographical code. The patients' addresses were geocoded to the counties of the study area. Skin cancer sites were categorized based on sun exposure in male and female cases. We used the empirical Bayesian smoothing approach to estimate the skin cancer incidence rate at the county level. Finally, Anselin's Local Moran's Index was used to identify the high-risk skin cancer occurrence areas.

Results: In general, skin cancer incidence increased in the study area over the study period (mid-March 2011 to mid-March 2017). Out of 4302 patients with skin cancer, 2602 cases (60\%) were male. The ageand sex-specific rate of reported cases with skin cancer was higher in the 80-89 age group (in both male and female genders) compared to other age groups. There were some high-risk spatial clusters of skin cancer in the study area. Further investigations are required to identify the underlying cause of the formation of these clusters.

Conclusions: Patients exposed to sunshine, especially among the male group, experienced much higher rates of cancer occurrence as compared to unexposed individuals. With a heterogeneous spatial pattern, hotspots were identified in non-sun-exposed and sun-exposed categories in the study area. Researchers and policymakers can significantly benefit from the spatial analyses of skin cancer incidence. These analyses can provide useful and timely prevention policies as well as tailored monitoring techniques in high-risk regions.

\section{Introduction}

Skin cancer is among the most abundant categories of cancer with an increasing global trend of occurrence. (1). Malignant melanoma (MM) and Non-Melanoma Skin Cancer (NMSC) are the two main skin cancer types. NMSCs are categorized as Basal Cell Carcinoma (BCC), Squamous Cell Carcinoma (SCC), and Bowen's disease. The incidence of NMSC and MM is on a growing trend, and in older adults aged over 50 , the rate of MM is on a rise of $0.6 \%$ annually (2). In Iran, it is also reported that skin cancer is more prevalent compared to other types of cancer, and BCC is the most common morphologic form of skin cancer in this country (3). Based on Ghoncheh et al.'s study in 2015, Fars' province had the highest incidence rate of skin cancer in southern Iran (4).

The different geographical patterns of skin cancer may be due to individual characteristics or environmental factors. According to previous studies, individual factors include being in declining years, male gender, having white skin or colored eyes, and race. Some environmental factors are also 
associated with skin cancer incidence rate. To illustrate, outdoor activities, environmental pollution, and radiation exposure have been previously documented in the literature (5). The elevated prevalence in the male gender accounts for higher sunshine exposure without suitable protection during outside activities. In numerous occupational circumstances, individuals are unprotected when exposed to ultraviolet (UV) radiation (6). Long term exposure to UV radiation in sunlight is well recognized to be responsible for most NMSCs in humans (7). Melanoma, SCC, and BCC manifestations have been correlated with diverse geographic locations as well as the amount of UV radiation (8). Based on a study conducted in Germany, sunshine hours and regional UV radiation have a considerable effect on skin cancer prevalence in this country (9).

Using a spatial methodology allows defining region-based patterns and trends associated with health outcomes, risk factors, and community wellbeing (10). Geographic Information System (GIS) is a computerized framework for storing, preserving, processing and presenting geographic information. This system is one of the emerging technologies that can facilitate the quality of health services and public health policy (11). GIS can be considered as a decision-making instrument in which spatial data is analyzed. This tool has become invaluable for recognizing and addressing health issues in various geographic sectors (12). In some studies and projects, spatial analysis methodologies were utilized in medical research (specifically cancer research). In a study by Montazeri et al. (2020), the incidence rates of breast and prostate cancers in Kerman, Iran, were calculated. The researchers utilized Anselin Local Moran's / to investigate outliers and clusters across all patterns of cancer. It was concluded that the incidence rate of both types of cancer was significantly higher than the average in the north-western region (13). In another study by Halimi et al. (2019), the pattern of colorectal cancer incidence in Hamedan, Iran, was calculated, and the same method of Anselin was used to explore the spatial clusters of colorectal cancer. There were high geographical disparities in the incidence of this cancer in the study area (14).

On the specific topic of skin cancer, there are several studies in which spatial analysis of skin cancer was performed in different geographical settings. Cecconi et al. (2016) analyzed the incidence data of melanoma and lip cancer utilizing the cancer registry of the Friuli Venezia Giulia (FVG) region in Italy. In this study, Bayesian hierarchical spatial models were employed to explain the spatial structure considering gender. Their research highlighted that the risk was incredibly significant for the coastal region and for body sites like the face and neck that are typically linked to high accumulated exposures, particularly in the male gender (15). In the study of Amancio and Nascimento (2014), spatial clusters of cutaneous melanoma incidence in Sao Paulo at the district level were identified. The researchers applied geostatistical techniques in addition to TerraView software to generate Moran maps, thematic maps, and Kernel maps. The research illustrated the spatial clusters with an elevated incidence rate of cutaneous melanoma (16). In another study, Ferreira and Nascimento (2016) aimed to discover the geographical variations of cutaneous melanoma deaths in southern Brazil by utilizing geo-processing methods. In that study, areas with high mortality rates due to the disease were distinguished and were suggested as a beneficial decision making aid for policymakers and managers (17). In the study of Hu et al. (2014), a spatial analysis was performed on melanoma patients' data in Florida. The researchers identified spatial 
clusters of high cancer incidence rates and established a model to predict cases in neighborhoods with an increased risk of incidence (18). In Ray et al.'s research in 2016, a methodology was developed using spatial scan statistics to identify BCC spatial clusters in the community of northern California, and the statistically significant BCC groups were discerned (19). Chang et al. (2010) used satellite imagery and remote sensing to examine the relationship between the intensity of UV radiation and skin cancer in sexual and ethnic groups in the United States. They revealed that men were more exposed to the radiation and more likely to develop skin cancer. It was concluded that the intensity of the radiation caused noticeable regional differences in different geographical areas in terms of cancer incidence (20).

In Iran, however, only a handful of relevant investigations have been undertaken regarding the geographic analysis of skin cancer. In the study of Zayeri et al. (2015), the high-risk regions of skin cancer at the province level were identified in Iran. The authors also investigated the relative risk of mortality and morbidity by skin cancer through spatial analysis. The researchers employed WINBUGS, ArcGIS, and fully Bayesian models for data analysis and identification of high-risk areas (21). Mohebbipour et al. (2015) utilized GIS to investigate the geographic distribution of BCC in Ardabil province. Necessary details such as age, gender, profession, and BCC site were derived from the patients' records. The results indicated that for cancer prevention, instructional measures should be given emphasis, and people should be educated on the use of personal protective equipment (22). Skin cancer incidence was investigated using spatial analysis by Pakzad et al. (2016) in a national study in Iran. They utilized Getis-Ord to identify disease hotspots, and eventually, high-risk zones were extracted (5).

The purpose of the present study conducted a geospatial analysis of skin cancer at the county level in the province of Fars, Iran. To the best of our knowledge, there is no study at a more satisfactory geographical level in Iran. Due to the limited research in this field in Fars, Iran, which considers sunshine exposure to different skin sites in each gender, we investigated the skin cancer incidence rate for each district of Fars province.

\section{Methods}

\section{Study Area}

Fars province is located in southwestern Iran, and its capital is the city of Shiraz. It extends about 122,608 $\mathrm{km}^{2}$, comprising 36 counties with a total population of 4,851,274 residents, according to the census results released by the statistical center of Iran in 2016 (23). Figure 1 illustrates the study area. Fars province is located in a geographical region where the average annual sunshine time is very high (9-9.4 hours per day) (24). According to the Fars Meteorological Organization reports, the long-term average temperature throughout the province is reported between 11 and $23^{\circ} \mathrm{C}$. In some parts of the province, throughout most of the summer, the temperature rises to $50^{\circ} \mathrm{C}$. Additionally, this area receives a large amount of UV radiation over the summer, with higher amounts of reported radiation in regions with high elevation (25). 


\section{Data Source}

The data on 4302 skin cancer cases recorded by Fars Cancer Registry over six years (mid-March 2011mid-March 2017) were used for statistical and spatial analysis. The variables included in the study were patients' residence address, gender, age, report date, and final topographical code. The patients' addresses were aggregated to the counties of the study area.

\section{Spatial analysis considering the presence of sun-exposure}

In this study, we sought to assess the relationship between skin exposure to sunshine in both genders and the probability of skin cancer incidence. Therefore, skin cancer sites were categorized based on sunshine exposure presence on male and female genders. Since in Iran, females have special clothing, the sunshine exposure to some parts of their body would be limited. For instance, in the female population, due to covering hair in public, the topographical site of "skin of scalp and neck" was considered without sunshine exposure. N/A (Not Applicable) means there was/were no/many specific site (s) of cancer on the body. Table 1 categorizes the topographical codes of skin cancer incidence along with their counts. As the table reveals, after "skin of other and unspecified parts of face" with 1945 patients, the "skin of scalp and neck" with 511 patients had the highest rate.

Table 1. The categorization of skin cancer sites based on sunshine exposure for each gender

\begin{tabular}{|llll|}
\hline Skin Cancer site & $\begin{array}{l}\text { ICD-10-CM Code } \\
\text { (Topography) }\end{array}$ & $\begin{array}{l}\text { Gender-based } \\
\text { Sun Exposure }\end{array}$ & $\begin{array}{l}\text { Count of cases in each } \\
\text { category in this study }\end{array}$ \\
$\begin{array}{l}\text { Skin of other and } \\
\text { unspecified parts of face }\end{array}$ & $\mathrm{C} 44.3$ & $\mathrm{M}: 1, \mathrm{~F}: 1$ & 1945 \\
\hline Skin of scalp and neck & $\mathrm{C} 44.4$ & $\mathrm{M}: 1, \mathrm{~F}: 0$ & 511 \\
\hline Skin, NOS & $\mathrm{C} 44.9$ & $\mathrm{~N} / \mathrm{A}$ & 442 \\
\hline Eyelid & $\mathrm{C} 44.1$ & $\mathrm{M}: 1, \mathrm{~F}: 1$ & 392 \\
\hline External ear & $\mathrm{C} 44.2$ & $\mathrm{M}: 1, \mathrm{~F}: 0$ & 302 \\
\hline Skin of lip, NOS & $\mathrm{C} 44.0$ & $\mathrm{M}: 1, \mathrm{~F}: 1$ & 212 \\
\hline Skin of trunk & $\mathrm{C} 44.5$ & $\mathrm{M}: 1, \mathrm{~F}: 1$ & 166 \\
\hline Skin of lower limb and hip & $\mathrm{C} 44.7$ & $\mathrm{M}: 0, \mathrm{~F}: 0$ & 156 \\
\hline $\begin{array}{l}\text { Skin of upper limb and } \\
\text { shoulder }\end{array}$ & $\mathrm{C} 44.6$ & $\mathrm{M}: 1, \mathrm{~F}: 0$ & 121 \\
\hline $\begin{array}{l}\text { Overlapping lesion of skin } \\
\mathrm{C}\end{array}$ & $\mathrm{C} 44.8$ & $\mathrm{~N} / \mathrm{A}$ & 55 \\
\hline
\end{tabular}


NOS:Not Otherwise Specified, M: Male, F: Female, N/A: Not Applicable, 1: With sun exposure, 0: Without sun exposure

\section{Empirical Bayesian Smoothed (EBS) approach}

We used the EBS approach to prevent the potential bias that may become evident in the incidence rates of sparsely populated locations. In this approach, smoothed estimates can be calculated using the local neighborhood. Accordingly, the local mean can be employed in lieu of the global mean (26). In other words, by utilizing this method, the incidence rates in the areas with limited populations and morbidities can be balanced (27).

\section{Cluster analysis}

We used the EBS incidence rate instead of the crude incidence rate. Also, cluster and outlier analyses were done using the Anselin's Local Moran's Index (ALMI) (28), and clustered maps were extracted. This test calculates the $\mathrm{p}$-value and z-score to illustrate and compare the apparent similarity. When the target area is surrounded by regions with identical rates of skin cancer, Low-Low (LL: low-risk area of cancer incidence) and High-High (HH: high-risk area of cancer incidence) concepts are used (positive correlation). High-Low (HL) and Low-High (LH) areas illustrate the dissimilarities and outliers of skin cancer incidence (negative correlation) (29).

\section{Hotspot analysis}

We used Getis-Ord Gi* statistic for hotspot analysis. This measure examines spatial association at a local scale by comparing the sum of all feature values and the local sum of the values for the relevant features and the importance of its surrounding features (30). Using this statistic, we measured hotspots or high-risk areas $(31,32)$ based on sunshine-exposure separation.

\section{Software}

QGIS 3.16.1, a cross-platform and open-source desktop GIS application (33), was used to create the study area map. Microsoft Excel 2016 and IBM SPSS Statistics 20 were utilized for data preprocessing, descriptive analysis, and chart creation. ArcGIS 10.8 (ESRI, Redlands, CA, USA) and GeoDa were used for spatial analysis. GeoDa is a free and open-source software tool for modeling and developing spatial patterns (34).

\section{Results}

\section{Descriptive results}

Skin cancer incidence in the study area had an increasing trend during the study period (mid-March 2011 to mid-March 2017). Of 4302 patients with skin cancer, 2602 cases (60\%) were male. Figure 2 illustrates 
the age-standardized distribution in all patients with skin cancer. According to this chart, the rate of reported skin cancer cases in the 80-89 age group (in both male and female genders) was higher compared to other age groups. The distribution of rates was further analyzed in the spatial findings section.

\section{Spatial results}

\section{Rate distribution}

The overall average cancer incidence rate was 71.66 (per 100,000). The incidence EBS rate average in the male group $(85.40$ per 100,000$)$ was higher than the female group $(60.02$ per 100,000$)$. In terms of total incidence rates, males with a value of 109.89 (per 100,000) had a higher cancer incidence rate than females $(81.25$ per 100,000$)$. The cancer average incidence rate in patients who were not exposed to sunshine was 7.14 (per 100,000). This rate increased to 64.96 in patients who were exposed to the sun. The rate in patients not exposed to the sun was 3.6 (per 100,000) in the male group and 10.94 (per $100,000)$ in the female group. However, the incidence rates in the sunshine-exposed group increased to 81.57 (per 100,000) in the male group and 49.4281 .57 (per 100,000) in the female group.

Figure 3 shows the maps of skin cancer EBS incidence rates by gender and category (SE: SunshineExposed or NSE: Non-Sunshine-Exposed). According to these maps, in an NSE status, the incidence rates in the whole study area were below ten (per 100,000) (Figure 3a) and represented a homogeneous geographical distribution pattern. As Figure $3 \mathrm{c}$ and Figure $3 \mathrm{e}$ illustrate, this homogeneous geographical pattern of low rates is repeated in male and female groups. The difference is that women's rate (10.94 per $100,000)$ was higher than men's (3.60 per 100000). But when patients were exposed to sunshine, a different pattern was observed.

Some counties experienced very high rates (more than 70 per 100,000) (Figure 3b) (including Mamasani, Abadeh, Kavar, Neyriz, and Shiraz). In the male group (Figure 3d), nearly $80 \%$ of counties experienced these high rates. In the female group (Figure $3 \mathrm{f}$ ), high rates are also seen in all counties, although only one county (Mamasani) had the highest rate $(74.82$ per 100,000$)$.

The result highlights a significant difference in the geographical distribution of EBS rates between the two categories, and in the male group, all counties experienced higher EBS incidence rates.

\section{Cluster analysis}

\section{Clusters/outliers}

To measure the spatial autocorrelation of incidence rates, ALMI was used. This approach shows the pattern of the geographical distribution of EBS rates on maps. The ALMI related maps are depicted in Figure 4. As established, based on total incidence EBS rates in NSE cases (Figure 4a), only two LH outliers were recognized, which included northwest counties. That is, the rates in these regions were lower compared to their neighbors. Again, in the same NSE category and the male group, a cluster (LL) in the 
northern region and an outlier (LH) in the southern area of the study area were formed (Figure 4c); the LL cluster highlights that the county itself had a very low rate and the neighbors also had low rates. In the female group (Figure 4e), in the NSE category, an outlier (LH) in the north, a cold spot (LL), and two hot spots $(\mathrm{HH})$ were formed in the center of the study area. $\mathrm{HH}$ clusters show that both counties (Sarvestan and Kharameh) had higher rates, and the neighbors also had high rates.

In the SE category, in terms of total EBS rates (Figure 4b), three HH clusters in the north, one LH outlier in the northeast, one HL outlier in the center, and LL clusters in the south were formed. The pattern of the male group (Figure $4 \mathrm{~d}$ ) almost follows the total EBS rates clustering pattern. The difference is that the number of LH outliers has increased in the northern regions. In the female group (Figure 4f), only one HH cluster and one LH outlier were formed in the northwest.

In summary, there is a diversity of spatial clusters and outliers in total EBS rates maps. The clustering pattern of the male group followed the pattern of total clustering. But in the female group, this clustering was significantly different and strongly random.

\section{Hot spot analysis}

Since the Z-score values obtained in the skin cancer EBS rates were higher than 1.96 in some areas, we used the Getis-Ord Gi* statistic to identify hot spots. Figure 5 shows the results of Getis-Ord Gi* statistic for cancer EBS rates in two categories (NSE and SE) for the study population (Total, male, and female). Figure 5a illustrates the total skin cancer incidenceEBS hotspot map in the NSE category. According to this map, only one county in the northwest (Mamasani) was identified as a hotspot with higher Z-scores, lower $p$-values, and with $90 \%$ confidence. In this category and male group (Figure $5 \mathrm{c}$ ), three hotspots were identified in the northwest (Mamasani and Kazerun) and southwest (Mohr) with 90\% confidence. In the female group (Figure 5e), two hotspots were formed in the study area's central part with $95 \%$ confidence (Sarvestan and Kharameh).

Figure $5 b$ depicts the total skin cancer incidence EBS hotspot map in the SE category. Unlike the NSE group, in this category, three different counties (Shiraz, Kazerun, and Sepidan) were identified as hotspots with $90-95 \%$ confidence, which were all concentrated in the north-western area. In other words, the pattern of hotspots was different in the two categories. In the SE category and the male group (Figure $5 \mathrm{~d}$ ), two hotspots, Shiraz in the west and Kharameh in th center were formed with $90 \%$ and $95 \%$ confidence respectively. According to Figure $5 f$, the pattern of hotspots in the female group was different. In this group, two hotspots (Rostam in the northwest and Kazerun in the west) were formed in the study area with $90 \%$ and $95 \%$ confidence, respectively.

As a result, hotspots were formed mostly in the west and northwest. Also, the pattern of hotspots in the female group was different from the male group. Some counties (Mamasani) in the NSE category and some others (Shiraz) in the SE category were the most frequent hotspots.

\section{Discussion}


Our descriptive results demonstrate that the incidence of skin cancer has increased during the 6-year study period. In addition, the findings also show that $60 \%$ of the studied patients with skin cancer were male. The incidence of skin cancer in Fars province was 71.66 (per 100,000). Previous research has also pointed to the high incidence of skin cancer in this province across the country $(5,21)$. The results also show that most people with skin cancer were elderly (age 60-79). According to official reports, the study area has a high aging ratio (about $10 \%$ of the population are elderly). However, this did not lead to bias in our results because we used the age-specific cancer rate to compare age groups' incidence rate (35). In other words, skin cancer is significantly more pronounced in the elderly age groups. These findings are in accordance with previous research results $(5,15,19,21)$. Also, we found out that when people were exposed to sunshine, skin cancer incidence EBS average rates rise sharply (7.4 per 100,0000 in NSE to 64.96 per 100,0000 in SE cases). This increase was more significant in men $(81.57100,0000)$ than women (49.42 per 100,0000).

There are four key findings related to our spatial analysis that are further discussed and compared with related research. The first finding is that a different geographical distribution pattern of cancer incidence rates was formed between two categories (NSE and SE) and between males and females in the study area. This finding is consistent with the previous literature (36). In the first category, NSE, the distribution was homogeneous, and in the second category (SE), the distribution was heterogeneous. For example, according to our findings, Shiraz is a county with higher male cancer rates, as reported in another previous study (5). Others have confirmed the association between prolonged sunshine exposure and skin cancer $(5,21)$. Our results also show that although the whole studied area is affected by prolonged sunshine exposure, some areas have experienced much higher cancer rates (especially in the male group), which could be due to various reasons. This finding is also consistent with the study of Cecconi et al. (15), which concluded that the high rate of skin cancer in men and its association with intense sunlight exposure is quite consistent. They noted that men in Italy's coastal areas are subject to extreme sunshine exposure to take a sunbath. But in Iran and in Fars province, most parts of the face, neck and hands are unintentionally exposed to the sun as a result of daily activities. This finding may be explained by the idea that, in the whole study area, men are more likely to engage in outdoor social and economic activities than women.

The second finding (the ALMI results) shows a clear difference between the two groups (NSE and SE) and between the male and female groups in terms of spatial clustering. In the first category, a small number of $\mathrm{HH}$ clusters was formed, but in the second group, the number of $\mathrm{HH}$ clusters was higher and closely resembled a clustered pattern. Geographically, $\mathrm{HH}$ clusters were formed in the western and north-western regions, and LL clusters were often created in the southern and southeastern parts. There seem to be common factors in the north-western areas that have had a more significant impact on skin cancer incidence in some counties. This study showed that the incidence of cancer in men had a higher effect on the spatial clustering pattern. Previous studies $(5,16,19,37)$ have noted an association between the harmful sunshine exposure (e.g., UV) and high skin cancer rates in some areas and the formation of $\mathrm{HH}$ clusters in more populated areas (such as Shiraz in this case). As Augustin et al. (9) have pointed out, in addition to factors affecting the incidence of skin cancer, such as harmful sun rays, there are essential 
geographical factors (such as air pollution, elevation, and wind blow intensity) and socio-economic factors (the type of employment, population density, and age) that are involved in the formation of $\mathrm{HH}$ areas (high risk); This could be because of the fact that skin cancer is more common in men who work outdoors and have to stay exposed to sunshine for extended periods (38).

The third main finding (the results of Getis-Ord Gi* statistic) is the identification of hot spots in the study area based on EBS rates in two categories (NSE and SE) for the study population (Total, male and female). Hotspots are formed mostly in the west and northwest in two categories (NSE and SE). The hotspots pattern was different in the female and male groups, but there was a hotspot in both groups. Some counties in the NSE category and some others in the SE category were the most frequent hotspots. In the female group, two hot spots were formed in the NSE category. It seems to be due to individual, environmental, or social factors other than sunshine exposure. As mentioned above, some studies concluded that skin cancer is more common in men who work outdoors (38). Whereas other researchers have found hotspots $(5,17,18,20)$, the present study has identified two hotspots as high-risk areas (Shiraz and Kazerun), which can be prioritized for preventive or curative measures.

\section{Recommendations:}

Skin cancer seems to be a severe challenge in the coming years for areas where sunshine radiation's duration and intensity are high. Sustainable training for jobs that require prolonged exposure to sunshine is an essential step in preventing skin cancer in this group. Educating children from an early age to protect their skin against harmful sunshine radiation is an issue that needs to be addressed by education and healthcare policymakers. In regions where the duration and intensity of radiation are high, educational programs for promoting preventive tools are essential. Various other genetic, individual, and socio-economic factors are also involved in the incidence of skin cancer. Therefore, it would be useful to extend the current findings by studying the association between environmental variables such as sunshine duration and intensity, altitude, temperature, and air pollution using accurate data and patients' exact geographical location (point features data).

\section{Limitations}

The present study's limitations naturally include lack of access to accurate spatial data for skin cancer patients (point address) and accurately recorded data on UV radiation, sunshine duration, and intensity on a local scale. Despite these limitations, the present study has enhanced our understanding of the relationship between spatial patterns of skin cancer incidence rates (in two sex groups) and NSE/SE categories.

\section{Conclusions}

We identified the fact that the incidence of skin cancer increased from 2011 to 2017. Patients exposed to the sunshine, especially in the male group, experienced much higher incidence rates than those who were 
not exposed to the sun. With a heterogeneous spatial pattern, hotspots were identified in NSE and SE categories in the study area. It can be concluded that, in terms of total skin cancer incidence rates, hotspots were formed in and around densely populated areas. Researchers and policymakers can significantly benefit from the spatial analyses of skin cancer incidence. These analyses can provide useful and timely prevention policies as well as highly-considered monitoring techniques in high-risk regions.

\section{Abbreviations}

MM: Malignant Melanoma

NMSC: Non-Melanoma Skin Cancer

BCC: Basal Cell Carcinoma

SCC: Squamous Cell Carcinoma

UV: Ultraviolet

GIS: Geographic Information Systems

N/A: Not Applicable

NOS: Not Otherwise Specified

EBS: Empirical Bayesian Smoothed

GMI: Global Moran's Index

ALMI: Anselin's Local Moran's Index

LL: Low-Low

HH: High-High

HL: High-Low

LH: Low-High

API: Application Programming Interface

OSM: OpenStreetMap

NSE: Non-sun-exposure/exposed

SE: Sun -exposure/exposed 


\section{Declarations}

Ethics approval and consent to participate: This research was ethically approved by the Ethics committee of Shiraz University of Medical Sciences (Ethics code: IR. SUMS. REC.1398.1149). All experiments were performed in accordance with relevant guidelines and regulations. For retrospective study, the need for consent to participate was deemed unnecessary according to Ethical Committee of Shiraz University of Medical Sciences.

Consent for publication: Not applicable

Availability of data and materials: The datasets are available from the corresponding author on reasonable request.

Competing interests: The authors declare that they have no competing interests.

Funding: Shiraz University of Medical Sciences financially supported this research (Grant No: 17847).

Authors' contributions: PT, AM, and BK drafted the manuscript and participated in data analysis. SMM critically reviewed the manuscript. MM, MA, AR evaluated the data and methods clinically and did final check. AM is the principal investigator and research leader. All authors read and approved the final version.

Acknowledgments: We hereby express our sincere appreciation and gratitude to Shiraz University of Medical Sciences for financial support and data gathering.

\section{References}

1. Razi S, Rafiemanesh H, Ghoncheh M, Khani Y, Salehiniya H. Changing Trends of Types of Skin Cancer in Iran. Asian Pac J Cancer Prev . 2015;16(12):4955-8.

2. Apalla Z, Nashan D, Weller RB, Castellsague X. Skin Cancer: Epidemiology, Disease Burden, Pathophysiology, Diagnosis, and Therapeutic Approaches. Dermatol Ther (Heidelb). 2017;7(Suppl 1):5-19.

3. Afzali M. Epidemiology of skin cancer and changes in its trends in Iran. journal of kashan university of medical sciences. 2013;7:501-11.

4. Ghoncheh M, Koohi F, Salehiniya H. Epidemiology and trend of skin cancer incidence in southern Iran. Journal of Dermatology and Cosmetic. 2015;6(2):85-92.

5. Pakzad R, Ghoncheh M, Pournamdar Z, Pakzad I, Momenimovahed Z, Salehiniya H, et al. Spatial Analysis of Skin Cancer Incidence in Iran. A Asian Pac J Cancer Prev. 2016;17(S3):33-7.

6. Fartasch M, Diepgen T, Schmitt J, Drexler $H$. The relationship between occupational sun exposure and non-melanoma skin cancer: Clinical basics, epidemiology, occupational disease evaluation, and 
prevention. Dtsch Arztebl Int. 2012;109:715-20.

7. Ananthaswamy HN. Sunlight and Skin Cancer. J Biomed Biotechnol. 2001;1(2):49-.

8. Qureshi A, Laden F, Colditz G, Hunter D. Geographic Variation and Risk of Skin Cancer in US WomenDifferences Between Melanoma, Squamous Cell Carcinoma, and Basal Cell Carcinoma. Arch Intern Med. 2008;168:501-7.

9. Augustin J, Kis A, Sorbe C, Schäfer I, Augustin M. Epidemiology of skin cancer in the German population: impact of socio-economic and geographic factors. J Eur Acad Dermatol Venereol. 2018;32(11):1906-13.

10. Sahar L, Foster SL, Sherman RL, Henry KA, Goldberg DW, Stinchcomb DG, et al. GIScience and cancer: State of the art and trends for cancer surveillance and epidemiology. Cancer. 2019;125(15):2544-60.

11. Salehi F, Ahmadian L. The application of geographic information systems (GIS) in identifying the priority areas for maternal care and services. BMC Health Serv Res. 2017;17(1):482.

12. Fradelos EC, Papathanasiou IV, Mitsi D, Tsaras K, Kleisiaris CF, Kourkouta L. Health Based Geographic Information Systems (GIS) and their Applications. Acta Inform Med. 2014;22(6):402-5.

13. Montazeri M, Hoseini B, Firouraghi N, Kiani F, Raouf-Mobini H, Biabangard A, et al. Spatio-temporal mapping of breast and prostate cancers in South Iran from 2014 to 2017. BMC Cancer. 2020;20(1):1170.

14. Halimi L, Bagheri N, Hoseini B, Hashtarkhani S, Goshayeshi L, Kiani B. Spatial Analysis of Colorectal Cancer Incidence in Hamadan Province, Iran: a Retrospective Cross-Sectional Study. Appl Spat Anal Policy. 2019.

15. Cecconi L, Busolin A, Barbone F, Serraino D, Chiarugi A, Biggeri A, et al. Spatial analysis of incidence of cutaneous melanoma in the Friuli Venezia Giulia region in the period 1995-2005. Geospat Health. 2016;11(1):422.

16. Amancio CT, Nascimento LF. Cutaneous melanoma in the State of Sao Paulo: a spatial approach. An Bras Dermatol. 2014;89(3):442-6.

17. Ferreira FR, Nascimento LF. Mortality due to cutaneous melanoma in south region of Brazil: a spatial approach. An Bras Dermatol. 2016;91(4):437-41.

18. Hu S, Sherman R, Arheart K, Kirsner RS. Predictors of neighborhood risk for late-stage melanoma: addressing disparities through spatial analysis and area-based measures. J Invest Dermatol. 2014;134(4):937-45.

19. Ray GT, Kulldorff M, Asgari MM. Geographic Clusters of Basal Cell Carcinoma in a Northern California Health Plan Population. JAMA Dermatol. 2016;152(11):1218-24.

20. Chang N-B, Feng R, Gao Z, Gao W. Skin cancer incidence is highly associated with ultraviolet-B radiation history. Int J Hyg Environ Health. 2010;213(5):359-68.

21. Zayeri F, Kavousi A, Najafımehr H. Spatial analysis of Relative Risks for skin cancer morbidity and mortality in Iran, 2008-2010. Asian Pac J Cancer Prev. 2015;16(13):5225-31. 
22. Mohebbipour A, Alipour S, Ahari SS, Amani F, Farzaneh E. Investigating the geographical distribution of skin cancer (BCC type) in Ardabil province via GIS. Int J Res Med Sci; 2015; 3(8).

23. Population and Housing Censuses of 2016: Statistical Center of Iran; 2018 [cited 2020, November 21 ]. Available from: https://www.amar.org.ir/english/Population-and-Housing-Censuses.

24. Ahmadi $\mathrm{H}$, Ahmadi F. Evaluation of sunshine duration and temporal-spatial distribution based on geostatistical methods in Iran. Int J Environ Sci Technol. 2019;16(3):1589-602.

25. Fars Meteorological Bureau 2020 [cited 2020, December 13]. Available from: http://www.farsmet.ir/Default.aspx.

26. Marek L, Pászto V, Tucek P. Bayesian Mapping of Medical Data. Modern Trends in Cartography: Springer; 2014. p. 489-505.

27. Nyadanu SD, Pereira G, Nawumbeni DN, Adampah T. Geo-visual integration of health outcomes and risk factors using excess risk and conditioned choropleth maps: a case study of malaria incidence and sociodemographic determinants in Ghana. BMC Public Health. 2019;19(1):514-

28. Anselin L. Local Indicators of Spatial Association-LISA. Geographical Analysis. 1995;27(2):93-115.

29. Bagheri N, Furuya-Kanamori L, Doi SAR, Clements ACA, Sedrakyan A. Geographical outcome disparities in infection occurrence after colorectal surgery: An analysis of 58,096 colorectal surgical procedures. Int J Surg. 2017;44:117-21.

30. Kim SM, Choi Y. Assessing Statistically Significant Heavy-Metal Concentrations in Abandoned Mine Areas via Hot Spot Analysis of Portable XRF Data. Int J Environ Res Public Health. 2017;14(6).

31. Moons E, Brijs T, Wets G. Hot Spot Analysis: Improving a Local Indicator of Spatial Association for Application in Traffic Safety: Lecture Notes in Computer Science, vol 5072. Springer, Berlin, Heidelberg; 2008.

32. Shariati M, Mesgari T, Kasraee M, Jahangiri-rad M. Spatiotemporal analysis and hotspots detection of COVID-19 using geographic information system (March and April, 2020). J Environ Health Sci Eng. 2020.

33. QGIS: A Free and Open Source Geographic Information System 2020 [cited 2020, December 1 ]. Available from: https://qgis.org/en/site/.

34. GeoDa: An Introduction to Spatial Data Analysis 2020 [cited 2020, December 1]. Available from: https://geodacenter.github.io/.

35. Welfare MoCLaS. Study of aging indicators and forecasting the aging trend in Iran until 2040. Tehran; 2015.

36. Rohani-Rasaf M, Abdollahi M, Jazayeri S, Kalantari N, Asadi-Lari M. Correlation of cancer incidence with diet, smoking and socio-economic position across 22 districts of Tehran in 2008. Asian Pac $\mathrm{J}$ Cancer Prev. 2013;14(3):1669-76.

37. McKinley JM, Ofterdinger $U$, Young M, Barsby A, Gavin A. Investigating local relationships between trace elements in soils and cancer data. Spat Stat. 2013;5:25-41. 
38. Mackie R, Quinn A. Non-melanoma skin cancer and other epidermal skin tumours. Rook's Textbok of Dermatology (eds T. Burns, S. Breathnach, N. Cox and C. Griffiths). 2004:1801-50.

\section{Figures}

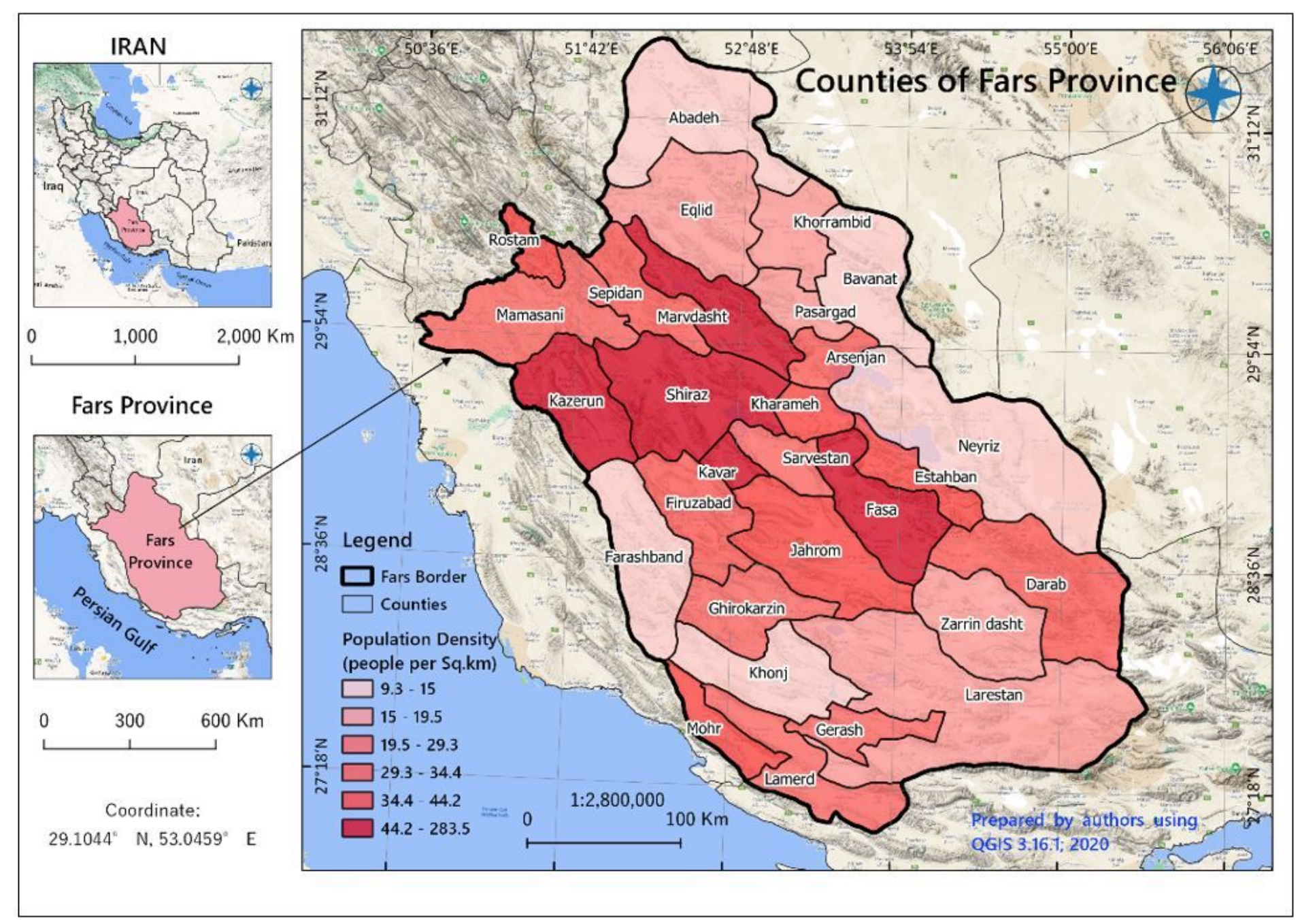

\section{Figure 1}

The geographic locations of each county in the province Note: The designations employed and the presentation of the material on this map do not imply the expression of any opinion whatsoever on the part of Research Square concerning the legal status of any country, territory, city or area or of its authorities, or concerning the delimitation of its frontiers or boundaries. This map has been provided by the authors. 


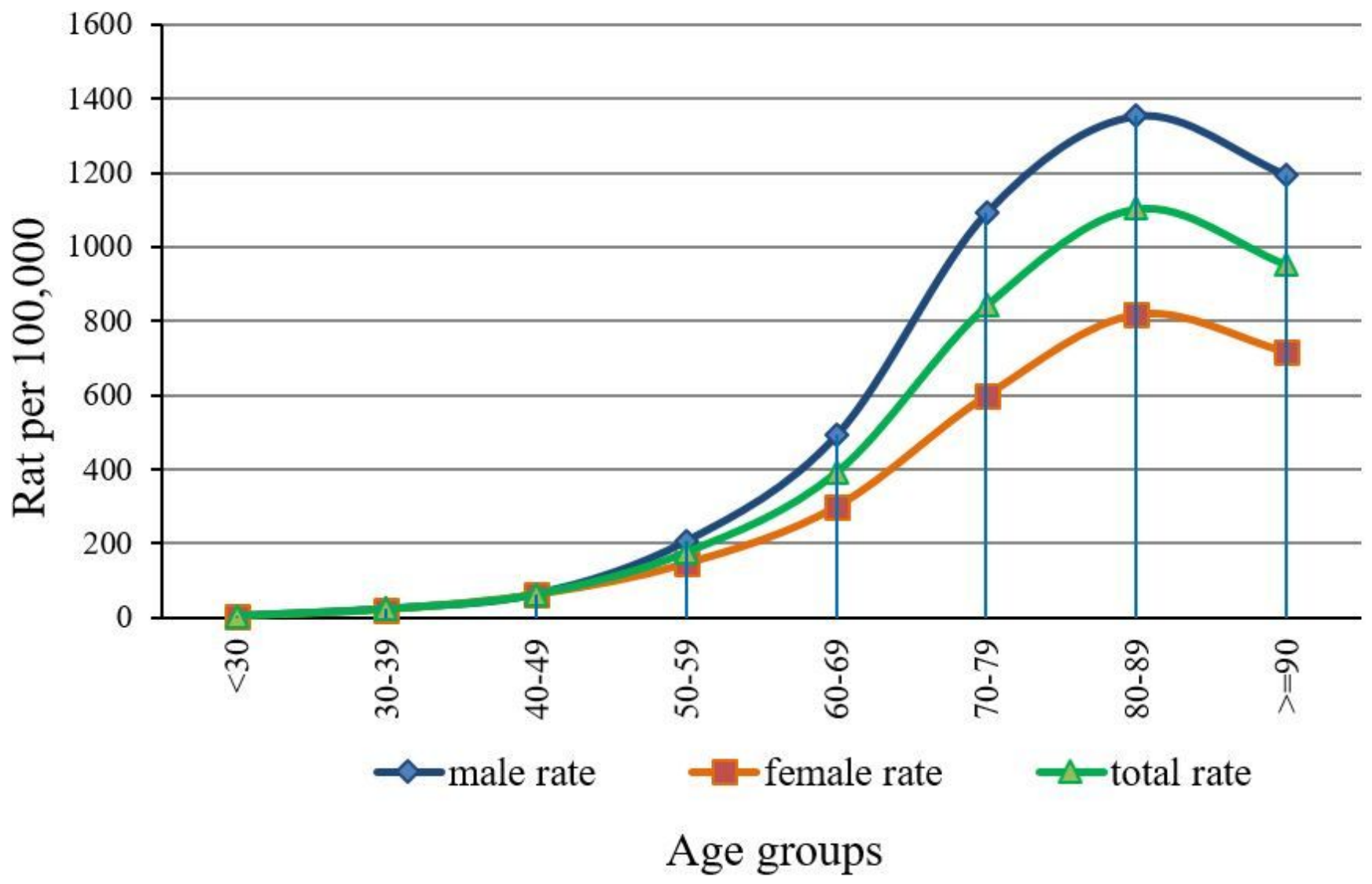

Figure 2

Age-standardized rate of skin cancer cases 

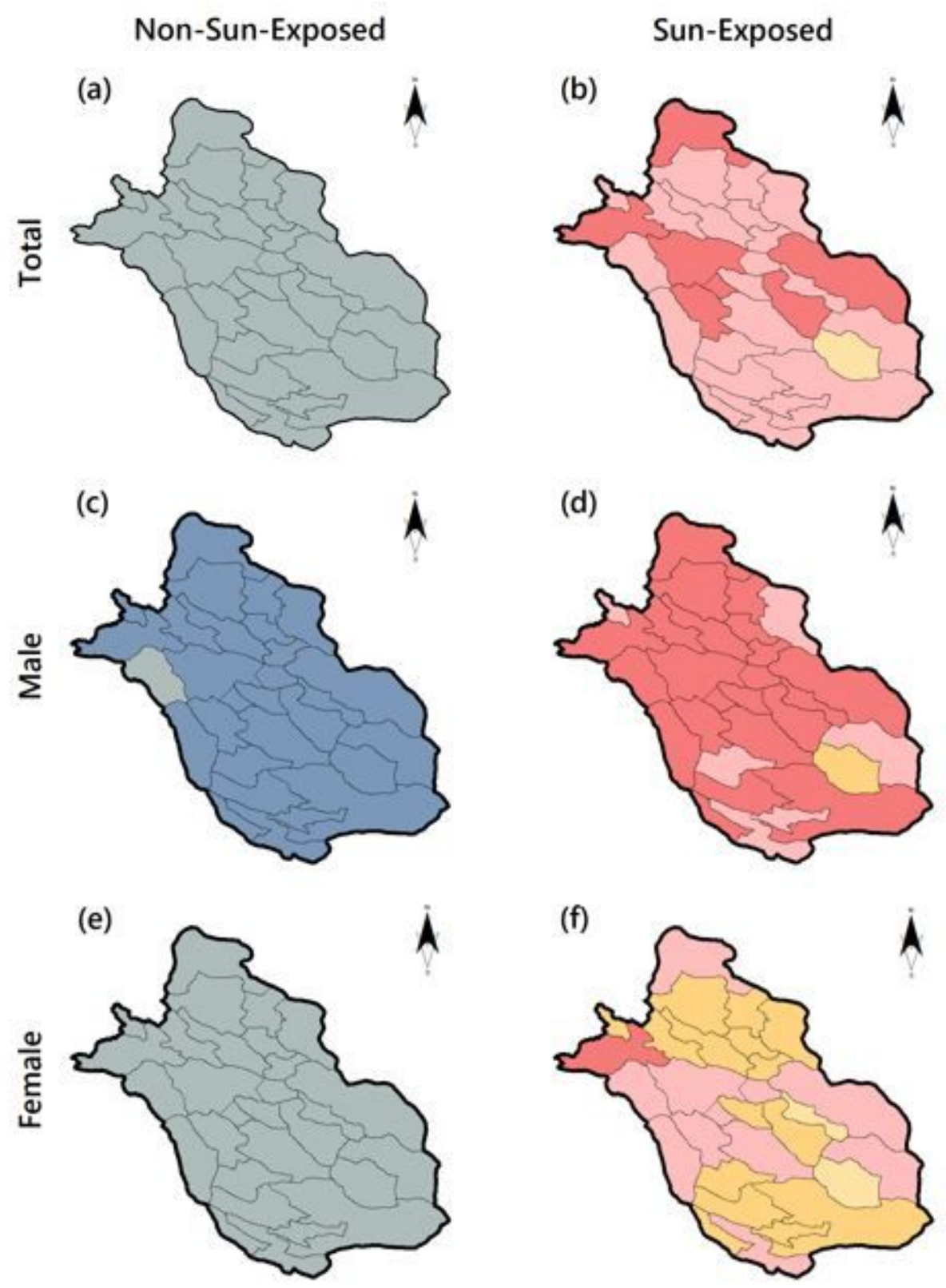

EBS Rate Maps
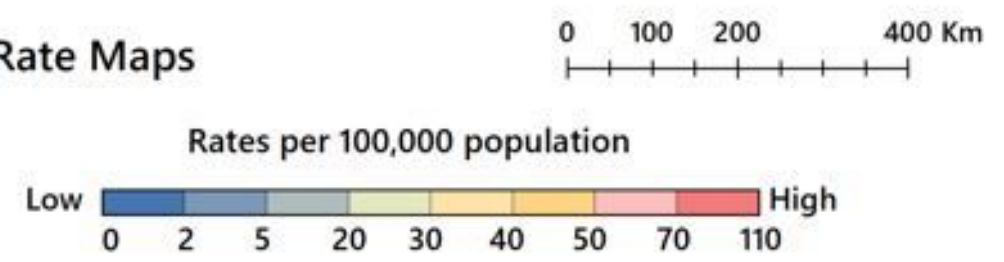

\section{Figure 3}

EBR rates of skin cancer in Fars Province based on gender and the probability of sunshine exposure Note: The designations employed and the presentation of the material on this map do not imply the expression of any opinion whatsoever on the part of Research Square concerning the legal status of any country, territory, city or area or of its authorities, or concerning the delimitation of its frontiers or boundaries. This map has been provided by the authors. 
Non-Sun-Exposed
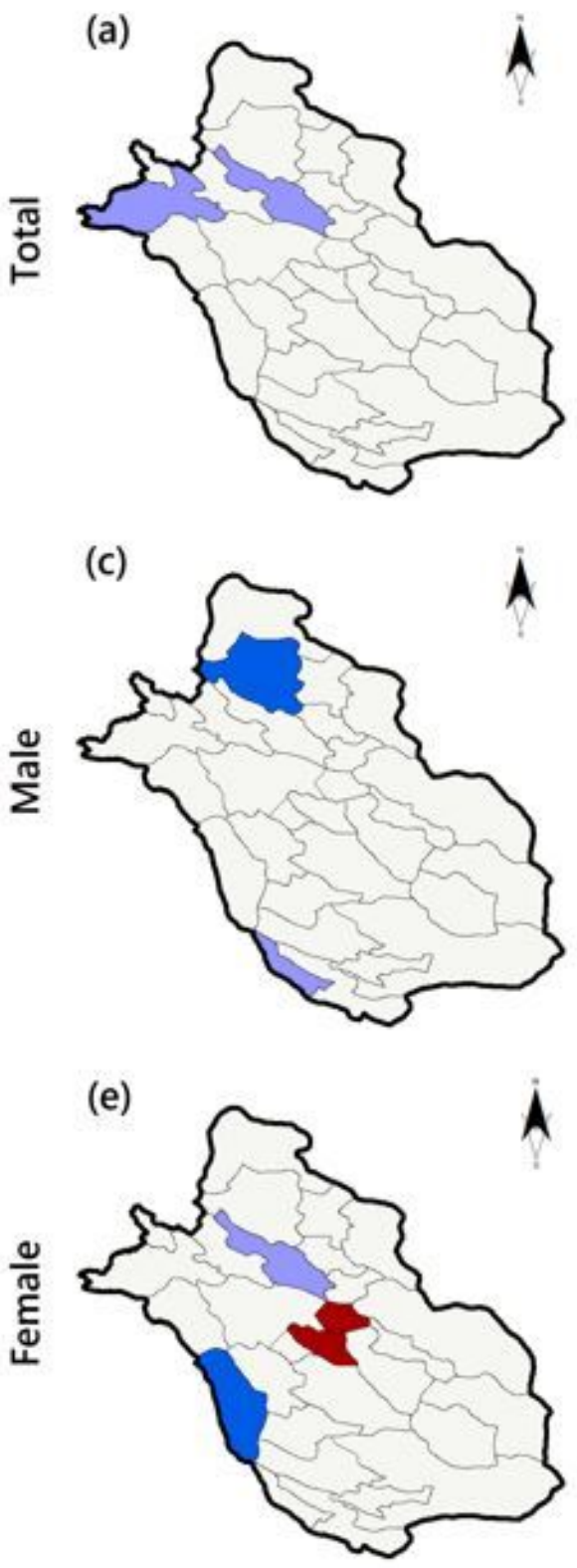

Sun-Exposed
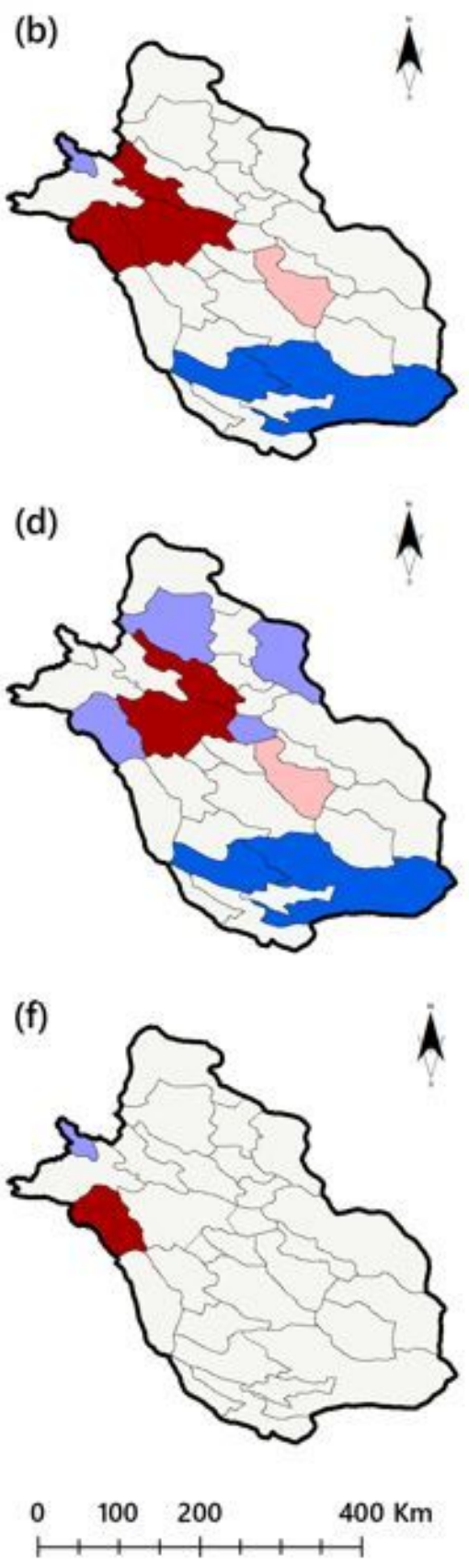

Cluster/Outlier (ALMI) Maps

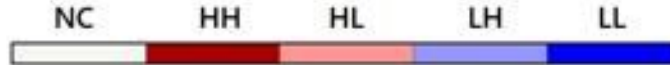

(Not Sig.) Cluster/Outlier type

\section{Figure 4}

EBR Cluster maps of skin cancer in Fars Province based on gender and the probability of sunshine exposure Note: The designations employed and the presentation of the material on this map do not imply the expression of any opinion whatsoever on the part of Research Square concerning the legal status of any country, territory, city or area or of its authorities, or concerning the delimitation of its frontiers or boundaries. This map has been provided by the authors. 
Non-Sun-Exposed
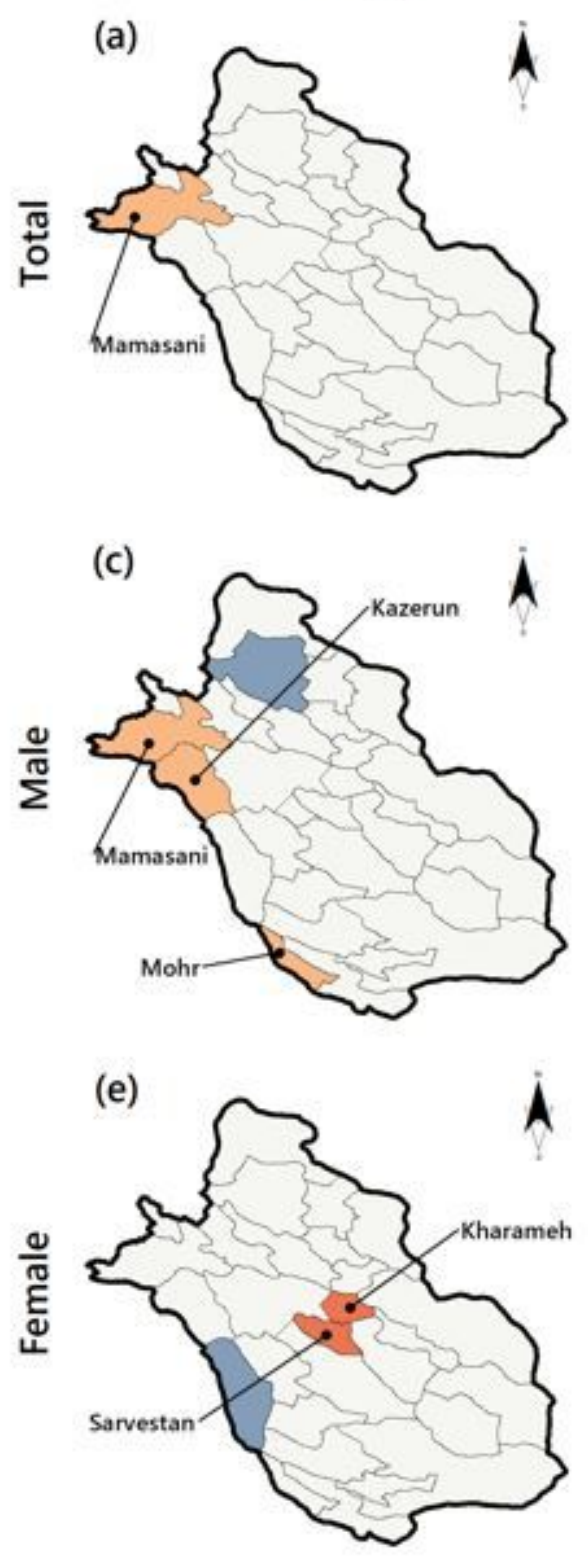

Getis-Ord Gi* (Gi_Bin) Gi_Bin

Cold Spot - 99\% Confidence Cold Spot - $95 \%$ Confidence Cold Spot - $90 \%$ Confidence Not Significant
Sun-Exposed
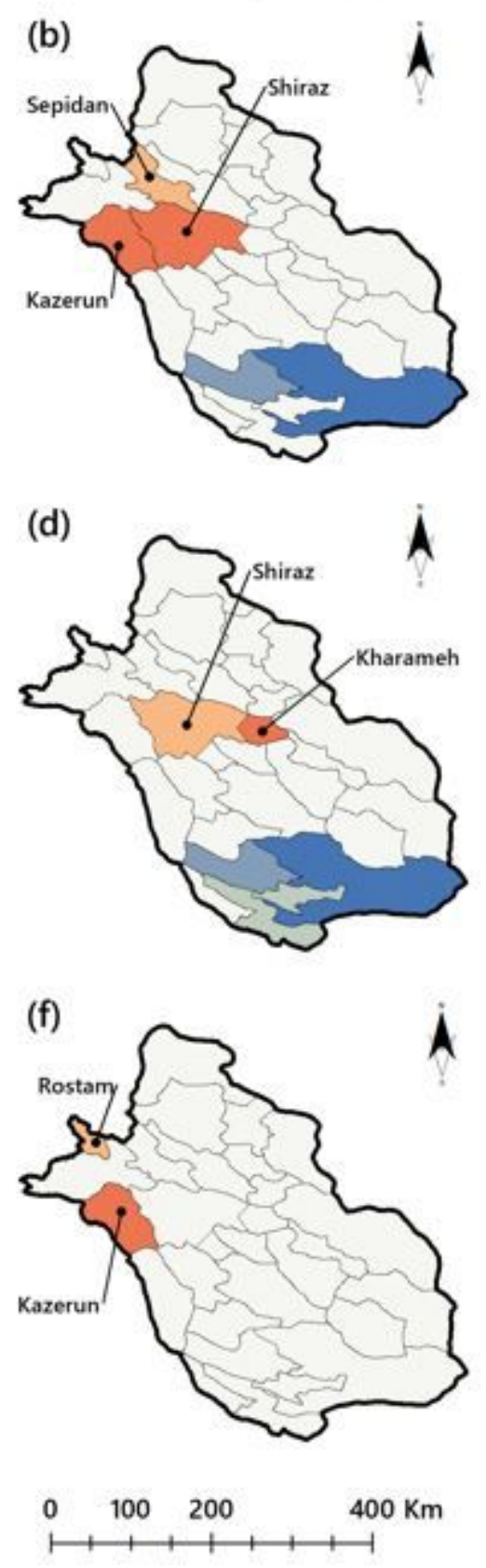

Hot Spot - 90\% Confidence Hot Spot - 95\% Confidence Hot Spot - 99\% Confidence

\section{Figure 5}

Hot spot and cold spots of skin cancer incidence in Fars province from mid-March 2011 to mid-March 2017 Note: The designations employed and the presentation of the material on this map do not imply the expression of any opinion whatsoever on the part of Research Square concerning the legal status of any country, territory, city or area or of its authorities, or concerning the delimitation of its frontiers or boundaries. This map has been provided by the authors. 